\title{
The Impact of Road Networks on Crime Rates in Saudi Arabia
}

\author{
Mofza Algahtany \\ School of Environment and Rural Science \\ University of New England \\ Armidale, New South Wales 2351 \\ Australia \\ and \\ Ministry of Justice \\ Riyadh, Saudi Arabia \\ Lalit Kumar \\ School of Environment and Rural Science \\ University of New England \\ Armidale, New South Wales 2351 \\ Australia \\ Elaine Barclay \\ School of Behavioural, Cognitive and Social Sciences \\ University of New England \\ Armidale, New South Wales 2351 \\ Corresponding author: Mofza Algahtany mofalgahtany@moj.gov.sa; +966114057777
}

\begin{abstract}
This study examined the influence of the quality and extent of road networks on crime rates in both urban and rural areas of Jizan province, Saudi Arabia. We performed both Ordinary Least Squares regression (OLS) and Geographically Weighted Regression (GWR) where crime rate was the dependent variable and paved (sealed) roads, non-paved (unsealed/dirt) roads and population density were the explanatory variables. Population density was a control variable. The findings revealed that across all fourteen districts, those with better quality paved road networks recorded lower rates of crime than the districts with unpaved roads. Furthermore, the more extensive the road networks, the lower the crime rate, whether the roads were paved or not. The findings concur with those of studies conducted in other countries which reveal that rural areas are not always the safe, crime-free places they are often believed to be.
\end{abstract}

Key words: crime, road networks, rural, Saudi Arabia 
This paper reports on the findings of a study that examined the influence of the quality and extent of road networks upon crime rates in both urban and rural places in Saudi Arabia. Specifically, the study considered the permeability of urban and rural areas; that is the degree of openness to traffic outside of a region that road networks might create and how that might provide opportunities for offending (White, 1990). The study was conducted in Jizan province in Saudi Arabia, a country where there has been little criminological research, largely due to the lack of access to official crime data, as well as social and economic data (Algahtany and Kumar, 2016). However, this is rapidly changing with advancements in new information technology (Algahtany, Kumar, Barclay \& Khormi, 2018).

The past three decades have seen criminologists turn their attention to examining the relationship between spatial factors and patterns in crime (Beavon Brantingham \& Brantingham, 1994; Brantingham and Brantingham, 2001; Brantingham and Brantingham, 1981a, 1984; Brantingham \& Brantingham, 1993a; Frank, Andresen \& Brantingham, 2012). In particular, the concept of 'place' has become an essential factor in crime analysis (Cohen \& Felson, 1979; Johnson, 2000).

According to crime pattern theory, crime rates are seen as a function of the physical structure (built environment) within a particular place (Brantingham \& Brantingham, 1993a). The main concepts within the theory are nodes, pathways and edges. Nodes refer to the places where people live and work. Nodes are connected by pathways which include streets, roads and highways that enable the movement of people, goods and services between areas, while edges refer to the boundaries of these areas (Brantingham \& Brantingham, 1993b; Sola, 2013). However, pathways also provide access to motivated offenders among those who utilise these pathways (Beavon et al., 1994). Consequently, streets and road networks are important spatial factors for inclusion in analyses and mapping of crimes (Lu \& Chen, 2007).

The safety and security of rural roads and city streets are fundamental to community wellbeing. However, while some studies have found a positive correlation between streets and crime, while others have found either a negative correlation or they found no evidence to link crime with streets. For example, studies by Jochelson (1997) and Groff and Lockwood (2014) both observed that the number of crime incidents accrued on streets or near streets where train stations, bars, subway stations, parks, schools and pubs were located. Yet Ridgeway and MacDonald (2017) examined if there was a link between rail station openings and crime rates in Los Angeles from 1990 to 2012 and found no evidence that these places or the surrounding neighbourhoods affected any change in crime. These previous studies have varied according to place and crime type and are reviewed in the next section.

Some researchers maintain that streets/roads provide opportunities for crime, especially where extensive and connected road networks offer offenders a greater selection of potential 
targets (Brantingham \& Brantingham, 1981b; Clare, Fernandez \& Morgan, 2009; McCutcheon, Weaver, Huff-Corzine \& Burraston, 2016). Beavon et al. (1994) examined the relationship between the accessibility of street networks, property crime and the concentration of potential targets for offenders in Maple Ridge and Pitt Meadows, British Columbia. Maple Ridge and Pitt Meadows are suburban communities of Vancouver, and include areas that are both developed and undeveloped in terms of commercial establishments, residential areas, and roadways. They found that areas that were more accessible had higher rates of crime than the areas that had less accessible roads. Also, they found that potential targets were significantly related to areas with a high number of accessible streets.

Other studies have found that controlling streets and closing them when needed can decrease crime and even prevent it. For example, according to a study conducted in Vancouver, British Columbia (Clarke, 2004), closing neighbourhood alleys and streets was important for preventing crime. The study confirmed that the more access to a street, the more crime occurred on that street. Sidebottom et al. (2018) agreed with Clarke that gating or closing alleys can reduce crime. White (1990) studied 86 neighbourhoods in the city of Norfolk in Virginia, U.S. and also found that neighbourhoods with high rates of burglary had more access points from arterial streets. Davies and Johnson (2015), in Birmingham (UK), tested if the spatial distribution of burglary offences was shaped by street networks and if the burglary risk was higher with greater usage of the street. They found a significant association between the burglary victimisation count and street segments that experienced high traffic. They also found that the more linear streets had a lower risk than street intersections. Poole, McCutcheon, Toohy, and Burraston (2018) examined the influence of road networks connectivity on criminal lethality in 190 cities in the U.S. They found that as road connectivity increased, lethality outcomes from criminal assault decreased while controlling for a variety of other factors that may act upon lethality.

From another perspective, researchers have found that streets with good lighting and various components designed to increase safety (Newman, 1995) can reduce both crime rates and fear of crime (Atkins, Husain \& Storey, 1991). Furthermore, it helps to increase pedestrian traffic on streets during the night time, which increases surveillance (Nubani \& Wineman, 2005). Street improvements, such as increasing lighting and ensuring streets are clean and tidy has positive effects for crime reduction and prevention. This leads to increased public confidence in the safety of an area and reduces fear of crime (Farrington \& Welsh, 2002; Welsh \& Farrington, 2008).

Most of these studies have examined how roads and road networks influence crime rates and how the environment affects an offender's decision to select potential targets and commit crime. However, only a few studies have examined the role major road networks may play in facilitating crime where these networds link rural areas to urban centres (Van Daele \& Vander 
Beken, 2011). McCutcheon et al. (2016) examined the relationship between interstate highways and rates of robbery across urban and rural counties within the southern state of Georgia in the U.S. They found that the number of interstate exits in a county significantly increased the robbery rate, and this relationship did not differ across urban and rural areas. Although rural areas recorded less robberies than urban centres, the more interstate exits in an area, the greater the rate of robbery. The authors concluded that highways bring more potential offenders to an area, and this may have a greater impact on rural communities. Van Daele and Vander Beken (2011) also found that neighbourhoods adjacent to major highways were more vulnerable to traveling offenders than were neighbourhoods located some distance from highways. Weaver, Corzine, Huff-Corzine, McCutcheon \& Vrbas (2014) further found that interstate highways in the US can act as drug corridors, increasing violent crime in a community. Altogether, these studies show that interstate road networks can have a major impact on crime rates in a community.

An important consideration is that road networks are also the means by which police maintain surveillance, enforce the law, and ensure public safety. Accordingly, road quality and accessibility is essential to enable police to effectively respond to crime incidents in a timely manner. Police effectiveness in rural areas is constrained by a lack of resources to pursue investigations across the large and diverse areas they must cover (Barclay, 2017).

From the literature, there appears to be two streams of thought concerning the relationship between roads/streets and crime. The first maintains that street and road networks are associated with high crime rates because they provide offenders with access to suitable targets. The second stream proposes that attending to street design can create a defensible space, which can reduce crime, increase safety and security, and reduce fear of crime. Theoretically, both approaches are true. However, most of the research in these areas have focused on urban areas. The present study asks if the quality and quantity of road networks throughout a country or region helps in crime reduction and prevention, or alternatively, increases the crime rate. Also, does the relationship between crime rates and road networks differ between urban and rural areas? The objective was to examine the association between crime rates and road networks within urban and rural areas within the Jizan region of Saudi Arabia. Using GIS and other spatial analysis techniques, the analysis compared the length and quality of road networks; that is the difference between paved (sealed) and non-paved (unsealed) roads (i.e. dirt roads) while controlling for population density within the 14 districts in Jizan.

\section{Study area and data sources}

Jizan province in Saudi Arabia is located along the southern border of Saudi Arabia with Yemen. Jizan had a population of 1,374,845 people in the last demographic survey in 2011 (General Authority for Statistics, 2017). Jizan's 14 districts has a total area of $11,671 \mathrm{~km}^{2}$ and a 
population density of 128 persons per $\mathrm{km}^{2}$ (General Authority for Statistics, 2017). Figure 1 displays the study area.

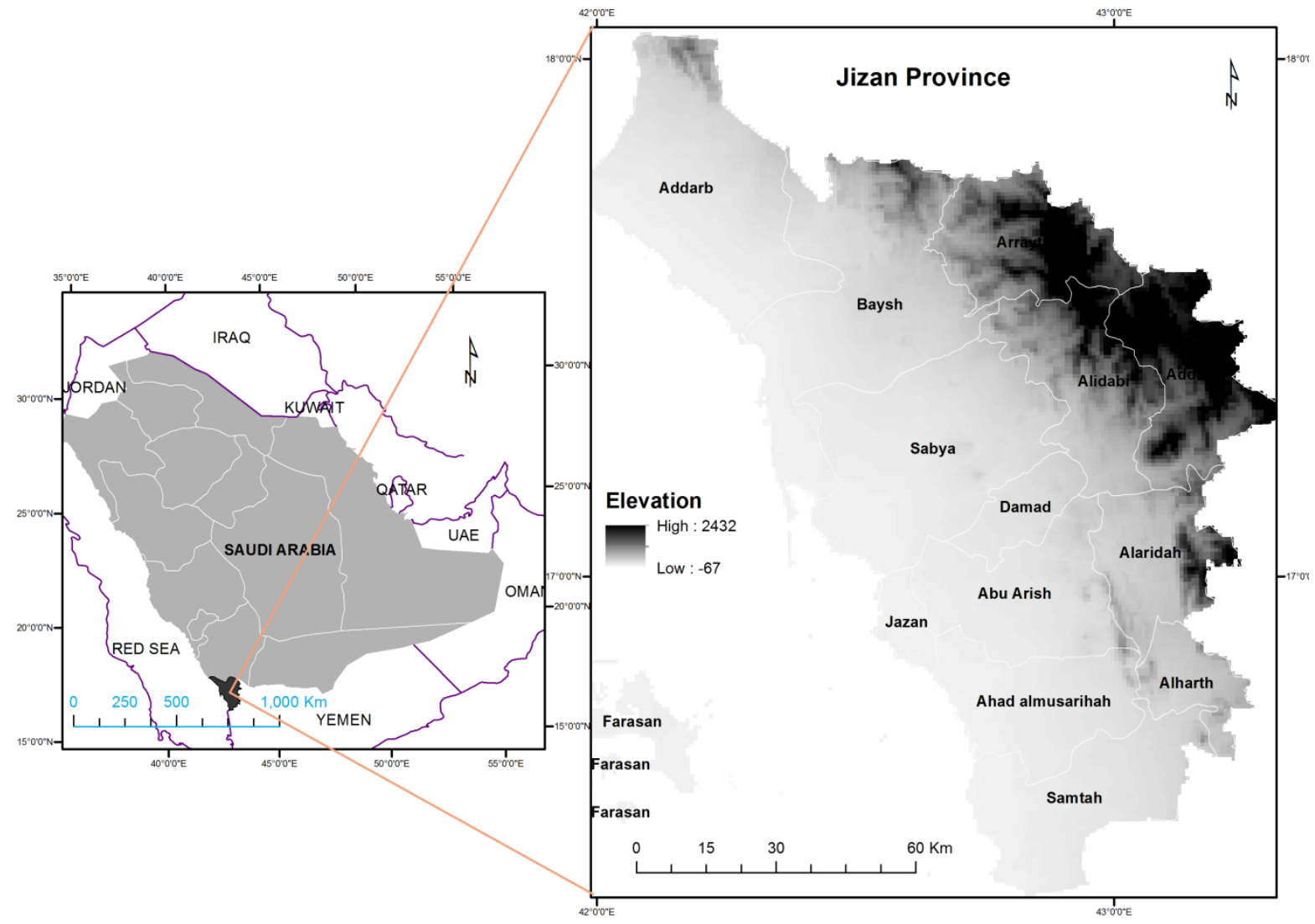

Figure 1: Study Area, Jizan province, Saudi Arabia

Crime data for each district are collected by the Saudi Ministry of Justice annually. They include the number of judicial rulings on cases of drug crimes, theft, murder, assault, alcohol offences, sexual assault, robbery and kidnapping (Ministry of Justice, 2005 - 2014). The data employed in the present study spans the 10 years from 2005 to 2014 . It should be noted that the crime data comprises cases that have been finalised judicially, by instrument or decision, which ensures the data have a high degree of accuracy (Algahtany, Kumar \& Khormi, 2014). However, it is a limitation of the study that data on crimes reported to and recorded by police, which are a better indicator of the nature and extent of crime, are currently unavailable to researchers in Saudi Arabia.

Annual population data for each district were obtained from the Saudi General Authority for Statistics. Jizan maps including transportation networks, shapefile, and district area were obtained from Geography Department of Jizan University. 


\section{Method}

\section{Data set}

The total number of criminal cases was divided by 10 to obtain the average of ten years from 2005 to 2014. This number was then divided by the population number for each of the fourteen districts in Jizan and multiplied by 10,000 to ascertain the rate of criminal cases per 10,000 people for each district. This data table was added to the spatial data layers that included the transportation networks and administrative boundaries of the districts. The transportation layer included two types of roads; paved roads and non-paved roads. This layer was then divided by Zonal Statistics Tool to identify the roads length in kilometres for each district separately. Population density was measured by the average population across ten years (2005 to 2014) divided by the area of each district.

An examination of rural crime requires a discussion of what is meant by the term 'rural'. Demographic definitions emphasise population numbers, density, and geographic isolation. However generally, the term 'rural' is used to describe non-urban or peripheral regions. One way of defining rural is determining what it is not (Barclay, Jobes, Donnermeyer \& Weinand, 2000). Here, urban and rural areas were defined by population density and the length of paved or unpaved roads in each district. Unpaved roads and low population density are more common within rural areas.

\section{Spatial analyses}

Both Ordinary Least Squares regression (OLS) and Geographically Weighted Regression (GWR) were implemented in the data analysis to identify which method was better able to measure the spatial relationship between crime rate as the dependent variable and road length and quality as the independent variables. Population density was an important control factor in the analysis as road quantity and location was related to population density.

In applying the OLS model, several assumptions were checked to measure the model fit to the data. Coefficients had the expected sign, there was no redundancy among explanatory variables, coefficients were statistically significant (probability and robust_Pr), residuals were normally distributed, adjusted $\mathrm{R}^{2}$ value was high for the model, and residuals (the model predictions) showed that there were no clusters that may affect the model.

GWR was then applied. The outputs of both analyses were compared and the GWR method was revealed as the better approach. In addition, GWR as a local regression builds an equation for each variable, giving a better result in a local scale and able to describe the variance in spatial relationships across the data (Getis, 2009; Nakaya, Fotheringham, Brunsdon \& Charlton, 2005). 
Akaike Information Criterion (AIC) in GWR was 401, while it was 411 in OLS which means GWR provided a better fit to the data.

The average number of criminal cases from 2005 to 2014 in each district per 10,000 population was specified as the dependent variable. Road length, paved roads, non-paved roads and population density were specified as the explanatory variables. Population density was a control variable.

The Kernel Density tool calculates the density of variables in a spatial area around those variables. It can be calculated for both point and line features. For instance, one spatial point (town) or line (road) might be weighted more heavily than others in determining overall crime rates. In this study, it has been used to identify crime density associated with paved and unpaved roads. Kernel was chosen as a fixed distance and bandwidth method, as using AIC to specify the kernel values was considered as the most important parameter of this regression.

\section{Results}

\section{Population density}

Jizan region is the most densely populated region in Saudi Arabia, with almost 100 persons per $\mathrm{km}^{2}$ (Algahtany, Kumar \& Khormi, 2016). Jizan city has the highest population density with around 462 persons per square $\mathrm{km}$. Farasan Island and Alrrayth have the lowest population densities in the region, with populations between 20 to 35 persons per $\mathrm{km}^{2}$. Damad, Abu Arish, Ahad Almusarihah, Alaridah, Samtah and Sabya have medium population densities in the region with a range between 160 to 280 persons per square km. Alharth, Baysh, Alidabi and Addaaer have a population density between 57 and 86 people per square $\mathrm{km}$ (see Figure 2). Addarb and Baysh are considered urban areas with larger populations compared to other areas. However, both have large areas that are not inhabited and where the people who live there are clustered near the main roads. This is why those two districts recorded a relatively low population density.

\section{Overall crime}

Figure 3 provides an overview of the rate of overall criminal cases per 10,000 people in the fourteen districts in Jizan region. Jizan city, Abu Arish, Ahad Almusarihah and Baysh have the highest rates of crime with around 248 to 450 cases per 10,000 people per year. Addarb has the second highest crime rate with about 83 cases. Samtah, Damad, Alidabi, Alharth, Sabya and Arrayth were almost similar, with between 32 and 64 cases. Alaridah, Farasan and Addaaer had the lowest crime rate cross the region. 
International Journal of Rural Criminology, Volume 4, Issue 2 (June), 2019

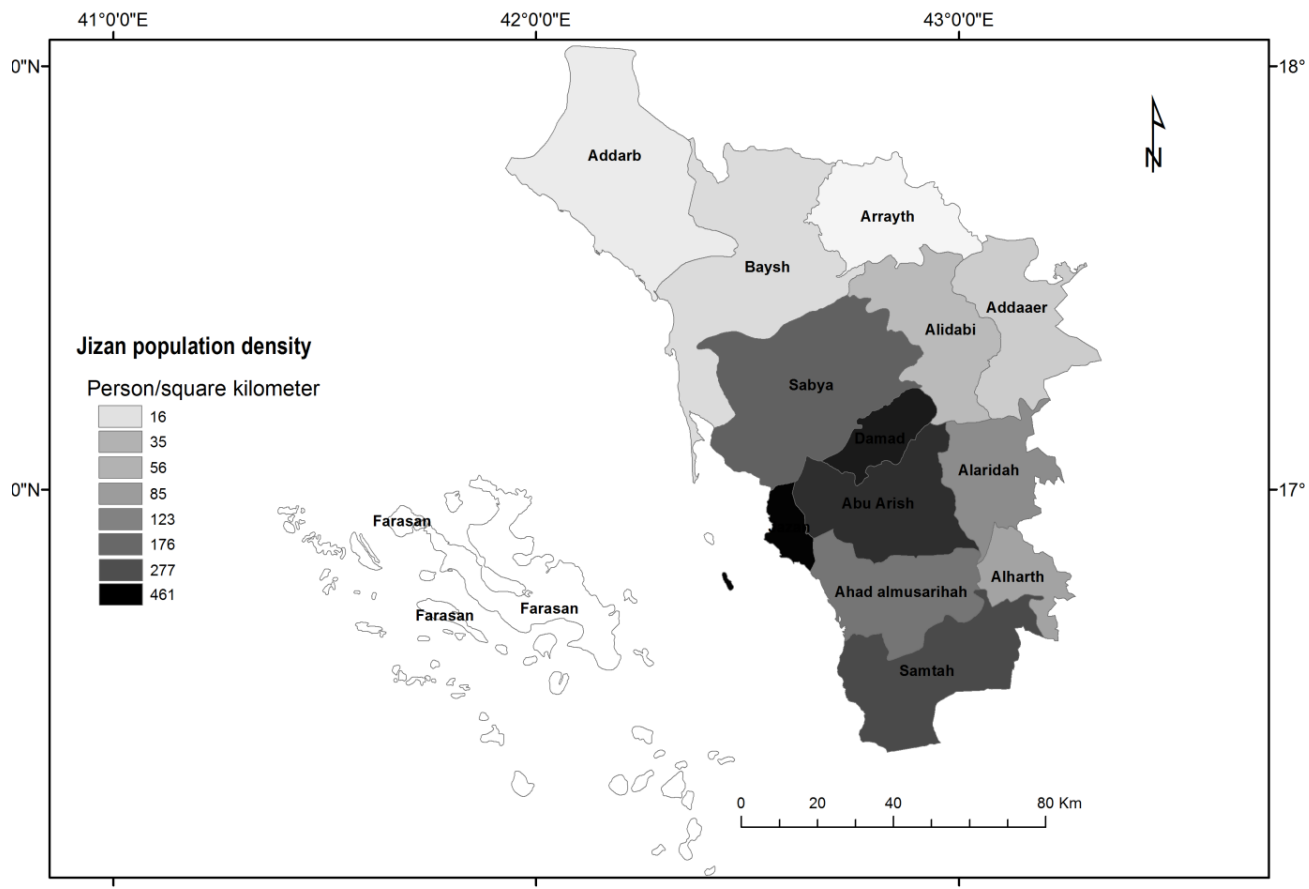

Figure 2. Districts in Jizan Region and Their Population Densities

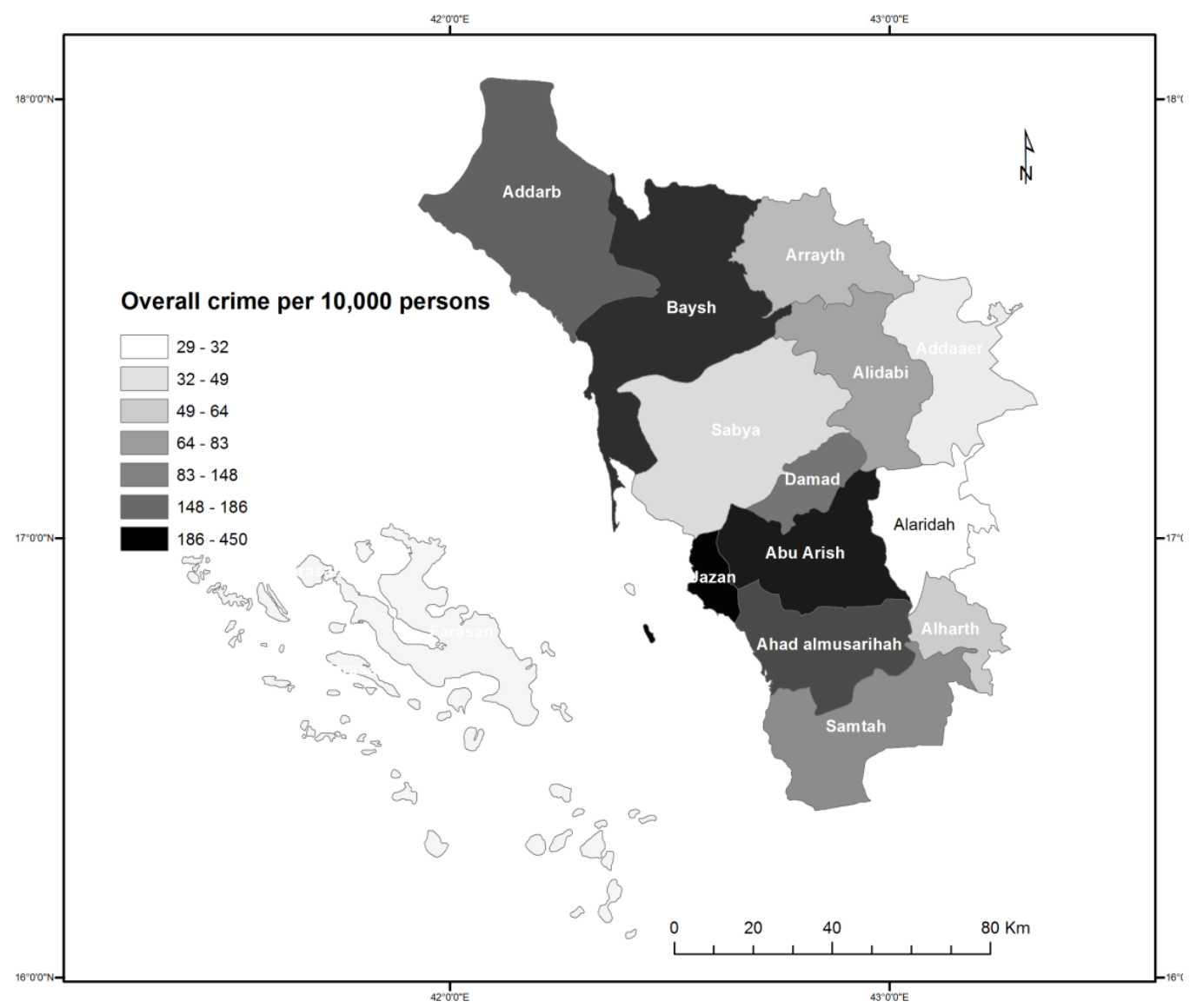

Figure 3. Overall Criminal Cases in Jizan 


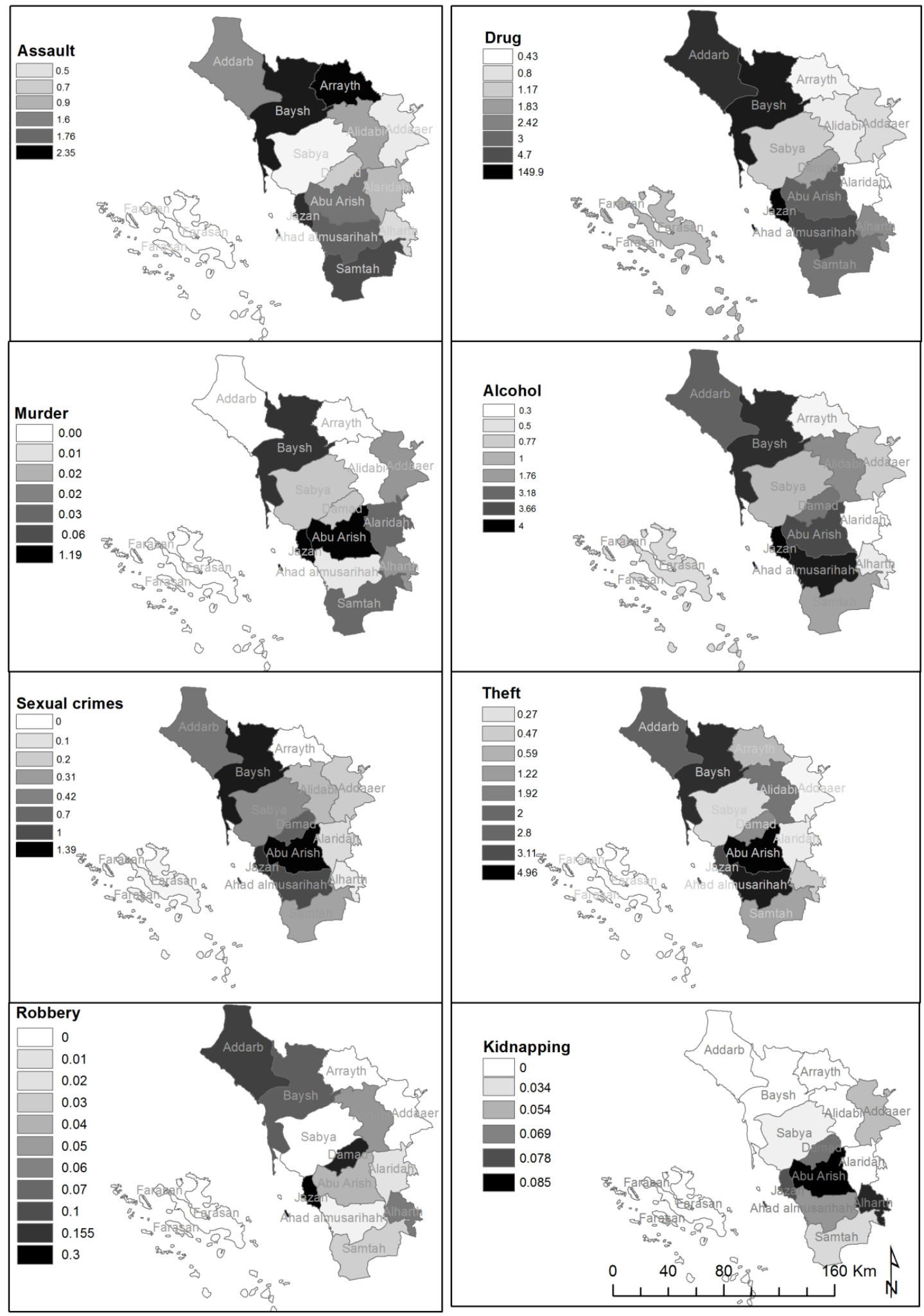

Figure 4. Spatial Distribution of Criminal Court Cases per 10,000 Persons in Jizan Districts 


\section{Crime overall in each district}

The spatial distribution of criminal activities (drug offences, theft, murder, assault, alcohol, sexual crime, robbery and kidnapping) per 10,000 population in Jizan districts are presented in Figure 4. Jizan city recorded the highest rate of all crimes, except for theft. This was followed by Baysh, which recorded one of the highest rates of assault, drug offences, murder, alcohol offences, sexual crime and theft. Ahad Almusarihah recorded high rates of assault, drug, alcohol and theft. Abu Arish experienced high rates of homicide, sexual offences, theft and kidnapping. Addarb recorded one of the highest rates of drugs and robbery. Arrayth and Samtah had a high rate of assault. Damad experienced high rates of robbery and Alharth high rates of kidnapping.

\section{Jizan roads}

Jizan has a large road network which links the 14 districts to the Asir region. A main international road also links Jizan with the neighbouring country of Yemen. Jizan roads are estimated to extend more than $6,000 \mathrm{~km}$ across the region. Around $2,800 \mathrm{~km}$ of these roads are not paved and many are located in very rough terrain, especially in the eastern districts which are mountainous areas, such as Alaridah, Arrayth, Addaaer and Alidabi (see Figure 5). Abu Arish, Samtah, Sabya and Ahad Almusarihah have the most paved roads of 425, 345, 253, $229 \mathrm{~km}$, respectively. Addarb, Farasan, Baysh, Alaridah and Damad each have paved road networks between 130 and $170 \mathrm{~km}$. Jizan city, Alidabi and Addaaer include around 90km for each; while Alharth has $48 \mathrm{~km}$ of paved roads. Arrayth had only $16 \mathrm{~km}$ paved roads. For unpaved roads, Abu Arish, Baysh and Addaaer were the districts with the most unpaved roads with $430 \mathrm{~km}$ for each. Alaridah, Addarb, Sabya and Alidabi contain between 335 and $375 \mathrm{kms}$ of unpaved roads for each district while Ahad Almusarihah, Alharth and Samtah have between 203 and 245km. Jizan city and Farasan have the least number of unpaved roads, with 29 and $39 \mathrm{~km}$ respectively.

\section{Crime and road networks}

Figure 6 indicates a negative relationship between road length and crime rates. The areas with more extensive road networks have a low crime rate compared with the areas that have fewer roads. However, to analyse this relationship further, regressions were applied to the data.

In OLS regression, Adjusted R-Squared was 0.62. Redundancy was checked among the explanatory variables (paved roads, non-paved roads and population density) where VIF values were low (between 1 and 1.5). Probability and Robust Probability revealed that all variables had statistically significant coefficients. Paved roads and population density were more significant than non-paved roads in the OLS regression model result. The Jarque-Bera was not statistically significant which means the model is not biased. AIC value was 411 . The Koeker (BP) test was 
statistically significant in the OLS, which meant that there were non-stationary relationships between one or more of the explanatory variables and the dependent variable. Where Koenker test is statistically significant, it indicates that results should improve by applying Geographically Weighted Regression. By moving to GWR, AIC value was better than the OLS value of 401. The Adjusted R-Squared was 0.807. Also, when testing the Spatial Autocorrelation tool on GWR the residuals were randomly distributed which indicates that the GWR model has better performance in data analysis (Figure 7). In the GWR results, maps have been represented in grayscale where the darker areas represent where the paved roads, non-paved roads and population density variables are strong predictors of crime rates, and moving to the lighter areas which represent those where variables are negatively related to crime rates. Figure 7 reveals that both paved roads and non-paved roads were strong predictors of crime rates in Alharth, Farasan, Samtah and Alidabi, while they were moderate predictors in Damad, Sabya and Arrayth.

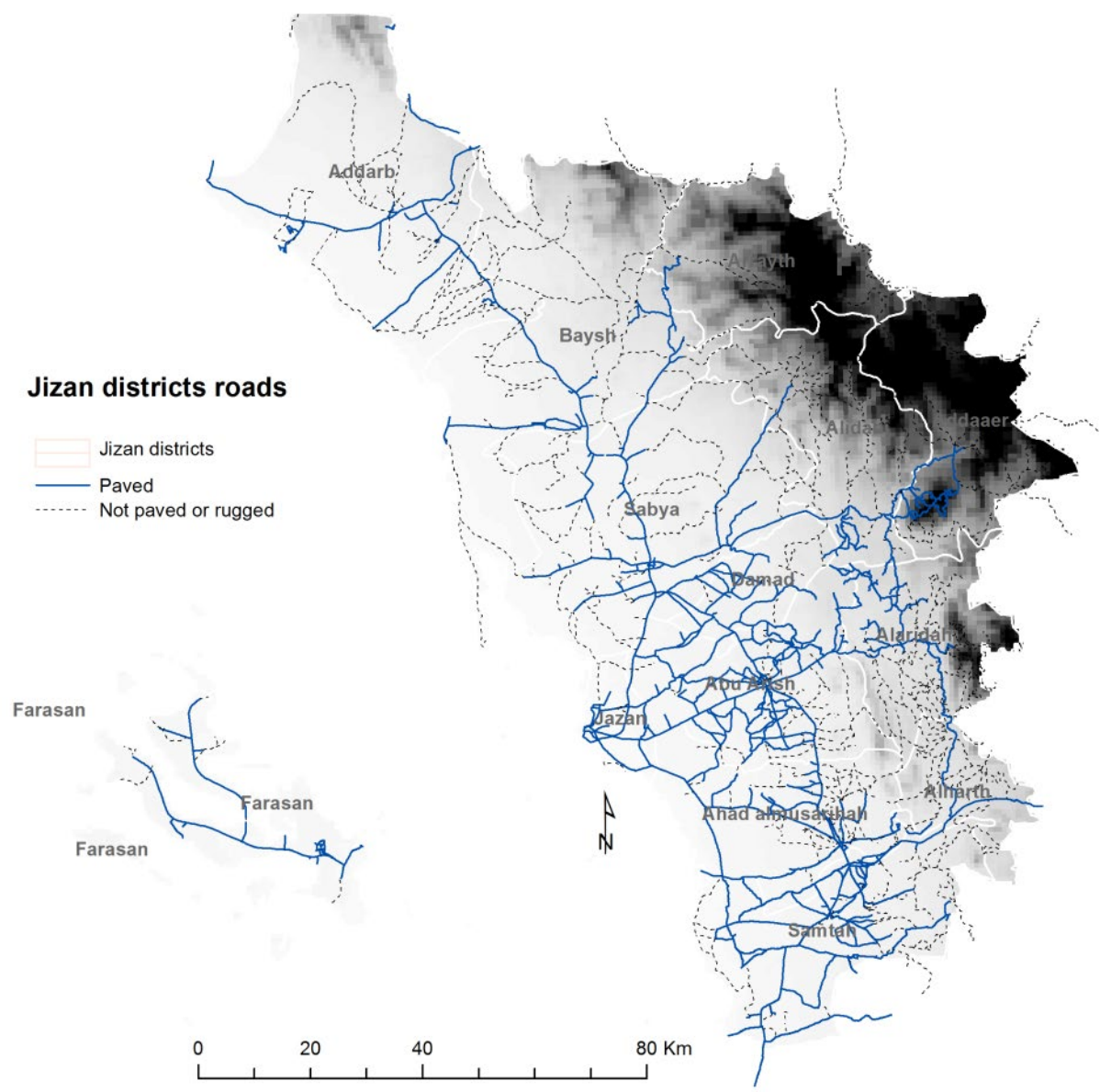

Figure 5. Jizan Districts Road Networks (data sourced from Jizan University) 


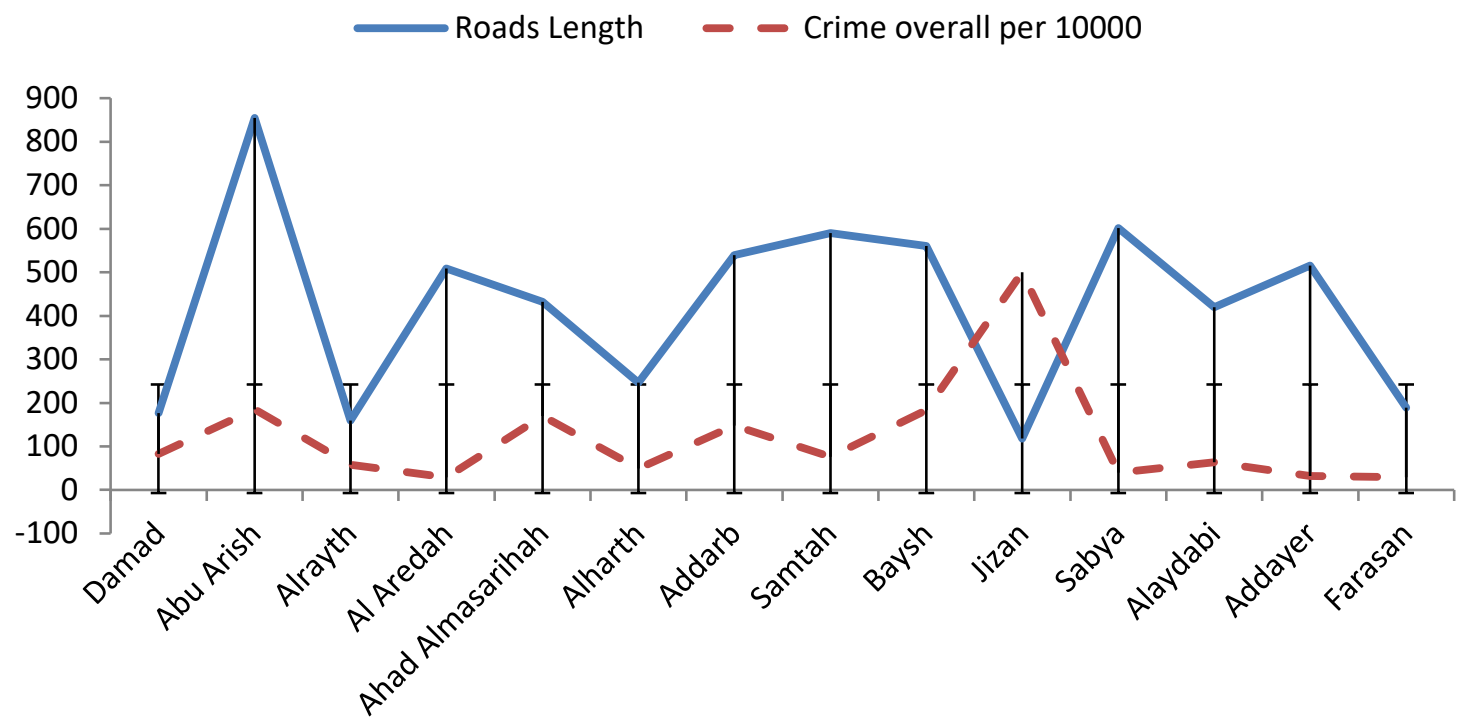

Figure 6. Crime and Transportation Networks in Jizan districts

From the Regression Coefficient table (Table 1), both paved roads and non-paved roads were found to be negatively related to crime rates with a coefficient of -2.42 for paved roads and almost -1 for non-paved roads. It suggests that the more extensive the road network the lower the crime rate irrespective of road quality.

Population density was a strong predictor of crime rates in six districts; Jizan city, Abu Arish, Ahad Almusarihah, Sabya, Baysh and Addarb. The coefficient of population density was 5.27 (see Table 1).

\section{Discussion}

Previous studies that have examined the relationship between street or road networks and crime have found variable results, depending upon the size of the study area and the focus of the study. Some studies explored the association between specific segments of a street, or type of street or road and crime. Other studies focused on how the environmental design of a street can create a defensible space to reduce crime and increase informal social control. The aim of this study was to examine how the extent and quality of road networks affect the crime rate across rural and urban areas of Jizan, Saudi Arabia. 

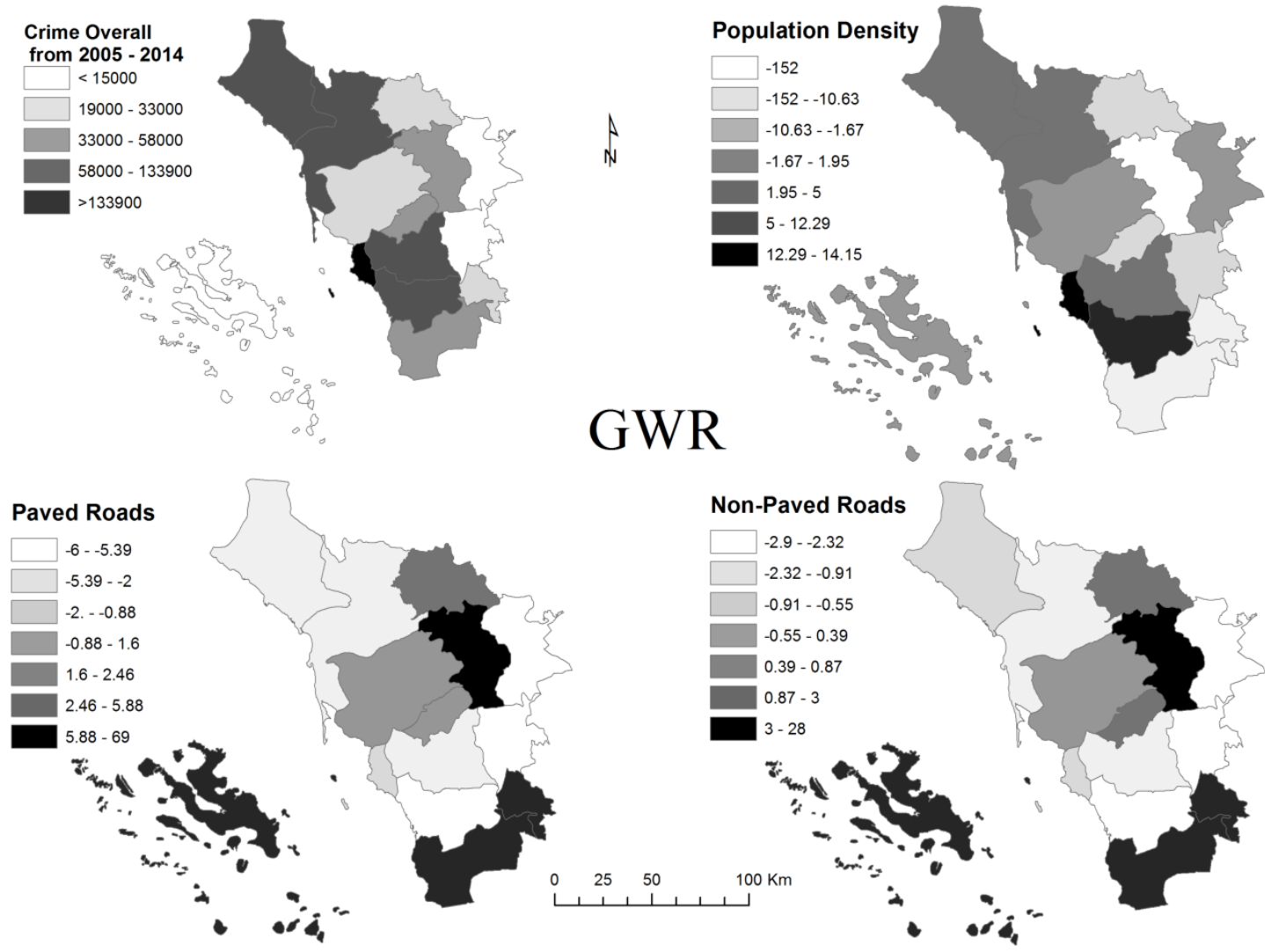

Figure 7. Crime Prediction Model in Jizan province

Table 1. The Regression Coefficients

\begin{tabular}{ll}
\hline Variable & Coefficient \\
\hline PAVED_RD & -2.418779 \\
NonPAVED_RD & -0.987712 \\
Population Density & 5.274258 \\
\hline
\end{tabular}

The findings revealed that high crime rates were significantly more likely to occur in areas of high population density. This finding is consistent with the literature that more crime occurs in places where there are more people (Barclay, 2017). Jizan city, Damad and Abu Arish were the most populated districts and had the greater amount of road networks. Yet these districts experienced low crime. From the results, it turns out that across all fourteen districts, those with better quality paved road networks recorded lower rates of crime than the districts with unpaved roads $(-2.42)$. The study further found that the more extensive the road networks, the lower the crime rate whether the roads were paved/sealed or not. 
Rural areas frequently experience different types of crime when compared to those in urban areas. In Jizan, the six districts located on the east of the province are considered to be rural areas. These areas have high rates of kidnapping, robbery, murder and drugs. Yet there are low rates of alcohol, assault, theft and sexual crimes, which is in contrast to urban areas which recorded high rates of these offences. Both urban and rural areas shared a high rate of murder and drug crimes. Public surveillance is not as effective in preventing crime in rural areas compared with urban areas. These findings create more questions which demand further research.

Closing streets is a common strategy in Saudi Arabia, where the police shut down some roads on occasion for security or organisational purposes. Other countries similarly apply these practices on some streets, especially in urban neighbourhoods, such as permanently closing off streets to create pedestrian malls (Clarke, 2004). As the literature explained, the streets with easy access experience more crime than areas with controlled or restricted access (Newman, 1995). Studies have consistently found that reducing traffic in streets or alleys by closing or controlling the streets can reduce crime in those areas. Informal surveillance is associated with increased pedestrian traffic in these areas, which leads to reductions in some types of crimes, such as robbery and burglary.

However, while walking is considered to be part of a healthy lifestyle in many western countries, this is not the case in Saudi Arabia, particularly in rural areas where people are more dependent upon motor vehicles. So, walking is not common and is rarely used in Saudi Arabia for going to work or to market stores. Thus there is less informal surveillance on Saudi streets. However, in rural areas, residents do know who does not belong in their area, which helps them to maintain guardianship over potential targets, such as homes. This can help in small communities or areas that do not have through roads.

Jizan province is a bordered region and the 14 districts of Jizan contain at least one main road which crosses the district to another, so, it is difficult to recognise strangers. That is why the findings in this study run counter to expectations that the informal surveillance of neighbourhoods and social control would be stronger in rural areas than in urban places within the Jizan region, and would be more predictive of low crime rates in rural areas. Most studies support the idea that burglars avoid houses in built up areas, unless these areas are situated far from the city centre or areas which are wooded or in wasteland areas that are easy to access. The findings concur with those of studies conducted in other countries which reveal that rural areas are not always the safe, crime-free places they are often believed to be (Donnermeyer \& Hollifield, 2003). For example, an analysis by crime type and geographic region across Australia revealed that rates of property and personal crime in many rural areas were actually higher than those in metropolitan areas (Barclay, 2017). 
Crime prevention depends on two important factors. Firstly, identifying the spatial point or hot spot of crime, and secondly, taking action to address the issue. Accordingly, attending to the environmental design and maintenance of the street to allow fast access by the police to any point of that street can maintain the safety of that street. The rural areas of Jizan, especially the eastern districts, are located in mountainous areas that have a rough terrain. This means that the police cannot respond in a timely manner to reports of crime. Easy accessibility to a neighbourhood is essential for police patrols to make the neighbourhoods safer and prevent crime.

In addition, most of the roads in the rural areas of Jizan are unpaved. However, the findings showed that these roads were still associated with lower crime rates where the effect was almost $(-1)$ in the analysis. In urban areas, it is simple to increase the police patrols in areas which experience a high rate of crime. Some studies have found an increase of police presence in an area can deter offenders in that particular area, but it is not enough to decrease crime overall (Townsley, 2017). Decreasing overall crime needs adequate analyses and research into the causes of crime. Also, it is easy to predict crimes in urban areas or at least types of crimes, while it is more difficult to do so in rural areas.

\section{Conclusion}

Transport systems, roads networks that enable the movement of people, goods and services, are vitally important in the social and economic development of any country. The study findings suggest that limited and poor quality road networks might increase the crime rate for certain offences in an area by inhibiting formal and informal guardianship in that area. Most previous research has looked at the connectivity and integration of neighbourhoods and crime, while this study explored the impacts and benefits of roads networks for crime reduction and prevention. The study found that the more extensive the road networks in a district, the lower the crime rate in that district.

The maps can play an essential role in helping security agencies effectively combat crime by paying more attention to surveillance within high crime areas. Such studies can help the police in assessing the safety of streets and road networks to target crime efficiently. It can help local authorities address the environmental features of streets and road networks that create opportunities for crime. Local authorities can use these findings to identify districts where the road networks need more attention and care, and prioritise those districts that require establishment of new road networks.

There is a lack of research on criminal activity in Saudi Arabia. However, it is expected that the findings of this research could be considered as an instrument for authorities in reviewing the current road network systems in the study area and the roads that cross the country 
in relation to crime rates. Further investigation into the effect of road networks upon different types of crime is also important. The recommendation for future research is to compare the results of this study with similar studies conducted in other countries and in other areas in Saudi Arabia to identify ways to make road networks safer. This study was limited by lack of access to data on social and structural factors that affect crime rates, such as social and economic disadvantage, unemployment, education, and geographic location such as the border of another country. With the increasing availability of such data, studies of the impact of the quality, location and extension of roads networks on crime in Saudi Arabia will be greatly enhanced.

\section{References}

Algahtany, M., \& Kumar, L. (2016). A method for exploring the link between urban area expansion over time and the opportunity for crime in Saudi Arabia. Remote Sensing, 8(10), 863. https://doi.org/10.3390/rs8100863

Algahtany, M., Kumar, L., Barclay, E., \& Khormi, H. M. (2018). The spatial distribution of crime and population density in Saudi Arabia. Crime Prevention and Community Safety, 20(1), 30-46. https://doi.org/10.1057/s41300-017-0034-3

Algahtany, M., Kumar, L., \& Khormi, H. (2016). Are immigrants more likely to be involved in criminal activity in Saudi Arabia? Open Journal of Social Sciences, 4(03), 170. https://doi.org/10.4236/jss.2016.43023

Algahtany, M., Kumar, L., \& Khormi, H. M. (2014). Spatio-temporal changes on crime patterns in Saudi Arabia from 2003-2012. Journal of Law and Social Sciences (JLSS), 4(1).

Atkins, S., Husain, S., \& Storey, A. (1991). The influence of street lighting on crime and fear of crime: Home Office London, UK.

Barclay, E., Jobes, P. C., Donnermeyer, J., \& Weinand, H. (2000). A qualitative and quantitative analysis of the relationship between community cohesiveness and rural crime. Part 1. Report to the Criminology Research Council Canberra.: Institute for Rural Futures, University of New England Publication No. 00-1.

Barclay, E. M. (2017). Rural Crime. In Deckert, A. \& Sarre, R. (Eds.), The Palgrave Handbook of Australian and New Zealand Criminology, Crime and Justice (pp. 285-297).

Basingstoke, United Kingdom: Palgrave. https://doi.org/10.1007/978-3-319-55747-2_19 
Beavon, D. J., Brantingham, P. L., \& Brantingham, P. J. (1994). The influence of street networks on the patterning of property offenses. Crime Prevention Studies, 2, 115-148.

Brantingham, P. J., \& Brantingham, P. (2001). The implications of the criminal event model for crime prevention. The process and structure of crime: Criminal events and crime analysis, 9, 227-303.

Brantingham, P. J., \& Brantingham, P. L. (1981a). Environmental criminology: Sage Publications Beverly Hills, CA.

Brantingham, P. J., \& Brantingham, P. L. (1981b). Introduction: The dimensions of crime. Environmental criminology, 7-26.

Brantingham, P. J., \& Brantingham, P. L. (1984). Patterns in crime. New York: Macmillan.

Brantingham, P. J., \& Brantingham, P. L. (1993). Environment, routine and situation: Toward a pattern theory of crime. Advances in criminological theory, 5, 259-294. https://doi.org/10.4324/9781315128788-12

Brantingham, P. L., \& Brantingham, P. J. (1993). Nodes, paths and edges: Considerations on the complexity of crime and the physical environment. Journal of Environmental Psychology, 13(1), 3-28. https://doi.org/10.1016/S0272-4944(05)80212-9

Clare, J., Fernandez, J., \& Morgan, F. (2009). Formal evaluation of the impact of barriers and connectors on residential burglars' macro-level offending location choices. Australian \& New Zealand Journal of Criminology, 42(2), 139-158. https://doi.org/10.1375/acri.42.2.139

Clarke, R. (2004). Closing streets and alleys to reduce crime: should you go down this road? Washington, D.C.: US Department of Justice, Office of Community Oriented Policing Services.

Cohen, L. E., \& Felson, M. (1979). Social change and crime rate trends: A routine activity approach. American Sociological Review, 588-608. https://doi.org/10.2307/2094589

Davies, T., \& Johnson, S. D. (2015). Examining the relationship between road structure and burglary risk via quantitative network analysis. Journal of Quantitative Criminology, 31(3), 481-507. https://doi.org/10.1007/s10940-014-9235-4 
Donnermeyer, J. F., \& Hollifield, C. A. (2003). Digital divide evidence in four rural towns. IT \& Society, 1(4), 107-117.

Farrington, D. P., \& Welsh, B. C. (2002). Effects of improved street lighting on crime: a systematic review: London: Home Office. https://doi.org/10.1037/e454542008-001

Frank, R., Andresen, M. A., \& Brantingham, P. L. (2012). Criminal directionality and the structure of urban form. Journal of Environmental Psychology, 32(1), 37-42. https://doi.org/10.1016/j.jenvp.2011.09.004

General Authority for Statistics, S. A. (2017). Population Statistics, Saudi Arabia. Retrieved from https://www.stats.gov.sa/en/node

Getis, A. (2009). Spatial weights matrices. Geographical Analysis, 41(4), 404-410. https://doi.org/10.1111/j.1538-4632.2009.00768.x

Groff, E. R., \& Lockwood, B. (2014). Criminogenic facilities and crime across street segments in Philadelphia: Uncovering evidence about the spatial extent of facility influence. Journal of Research in Crime and Delinquency, 51(3), 277-314. https://doi.org/10.1177/0022427813512494

Jochelson, R. (1997). Crime and place: An analysis of assaults and robberies in inner Sydney: NSW Bureau of Crime Statistics and Research, Attorney General's Department.

Johnson, C. (2000). Crime mapping and analysis using GIS. Paper presented at the Geomatics Conference on Geomatics in Electronic Governance, January.

Lu, Y., \& Chen, X. (2007). On the false alarm of planar K-function when analyzing urban crime distributed along streets. Social Science Research, 36(2), 611-632. https://doi.org/10.1016/j.ssresearch.2006.05.003

McCutcheon, J. C., Weaver, G. S., Huff-Corzine, L., Corzine, J., \& Burraston, B. (2016). Highway robbery: Testing the impact of interstate highways on robbery. Justice Quarterly, 33(7), 1292-1310. https://doi.org/10.1080/07418825.2015.1102953

Ministry of Justice, S. A. (2005 - 2014). Annual Statistical Book. Retrieved from https://www.moj.gov.sa/ar/Pages/default.aspx 
Nakaya, T., Fotheringham, A. S., Brunsdon, C., \& Charlton, M. (2005). Geographically weighted Poisson regression for disease association mapping. Statistics in medicine, 24(17), 2695-2717. https://doi.org/10.1002/sim.2129

Newman, O. (1995). Defensible space: A new physical planning tool for urban revitalization. Journal of the American planning association, 61(2), 149-155.

https://doi.org/10.1080/01944369508975629

Nubani, L., \& Wineman, J. (2005). The role of space syntax in identifying the relationship between space and crime. Paper presented at the Proceedings of the 5th Space Syntax Symposium on Space Syntax, Delft, Holland.

Poole, A. C., McCutcheon, J. C., Toohy, K., \& Burraston, B. (2018). Testing the impact of road network connectivity on criminal lethality. Homicide studies.

https://doi.org/10.1177/1088767918754307

Ridgeway, G., \& MacDonald, J. M. (2017). Effect of rail transit on crime: a study of Los Angeles from 1988 to 2014. Journal of Quantitative Criminology, 33(2), 277-291. https://doi.org/10.1007/s10940-016-9296-7

Sidebottom, A., Tompson, L., Thornton, A., Bullock, K., Tilley, N., Bowers, K., \& Johnson, S. D. (2018). Gating alleys to reduce crime: A meta-analysis and realist synthesis. Justice Quarterly, 35(1), 55-86. https://doi.org/10.1080/07418825.2017.1293135

Sola, O. O. (2013). Opinions of end users and transport professionals on the performance of roads In Ekiti State, South-West, Nigeria. European Scientific Journal, ESJ, 9(17).

Townsley, M. (2017). Crime mapping and spatial analysis. In LeClerc, B. \& Savona, E. (Eds.) Crime Prevention in the 21st Century (pp. 101-112). Cham, Switzerland: Springer. https://doi.org/10.1007/978-3-319-27793-6_8

Van Daele, S., \& Vander Beken, T. (2011). Outbound offending: The journey to crime and crime sprees. Journal of Environmental Psychology, 31(1), 70-78.

https://doi.org/10.1016/j.jenvp.2010.09.002

Weaver, G. S., Corzine, J., Huff-Corzine, L., McCutcheon, J. C., \& Vrbas, J. (2014). Highways to homicide: Interstates, drug markets, and violence. International Journal of Contemporary Sociology, 51, 117-145. 
International Journal of Rural Criminology, Volume 4, Issue 2 (June), 2019

Welsh, B. C., \& Farrington, D. P. (2008). Effects of improved street lighting on crime. Campbell Systematic Reviews, 13, 1-51. https://doi.org/10.4073/csr.2008.13

White, G. F. (1990). Neighborhood permeability and burglary rates. Justice Quarterly, 7(1), 5767. https://doi.org/10.1080/07418829000090471 